\title{
EMPREGO DE MATRIZ ÓSSEA ORGÂNICA BOVINA E HIDROXIAPATITA NO REPARO DE DEFEITO INDUZIDO EM CRÂNIO DE RATOS ${ }^{1}$
}

\author{
Fabiano Braz ${ }^{2}$ \\ Sheila Canevese Rahal ${ }^{3}$ \\ Noeme de Sousa Rocha ${ }^{4}$ \\ Eulázio Taga ${ }^{5}$ \\ Fernando de Biasi'
}

\begin{abstract}
Braz F, Rahal S C, Rocha N S, Taga E, Biasi F. Emprego de matriz óssea orgânica bovina e hidroxiapatita no reparo de defeito induzido em crânio de ratos. Acta Cir Bras [serial online] 2003 Jan-Fev;18(1). Disponível em URL: http://www.scielo.br/acb.

RESUMO - Objetivo: Avaliar a resposta biológica e poder indutor da combinação matriz óssea orgânica bovina e hidroxiapatita. Métodos: Foram produzidos defeitos ósseos em crânios de 20 ratos, Wistar, machos, com peso inicial médio entre 300 e 350 gramas, divididos eqüitativamente em dois grupos. No grupo I o defeito foi preenchido com uma associação de matriz óssea orgânica bovina e hidroxiapatita, ao passo que no grupo II considerado controle, nada foi empregado. Para o estudo histológico foram submetidos à eutanásia, cinco animais de cada grupo, aos 30 e 60 dias de pós-operatório. Resultados: Com 30 dias de pós-operatório a reabsorção óssea foi maior no grupo II. A presença de cartilagem não diferiu entre os momentos de um mesmo grupo, porém houve diferença estatística entre os grupos I e II aos 30 dias, sendo maior no grupo I. Aos 60 dias de pós-operatório, o grupo I apresentava uma maior quantidade de osteoblastos e presença de osso comparativamente ao grupo II. Conclusão: A combinação matriz óssea orgânica bovina e hidroxiapatita não causa reações adversas e favorece a reparação óssea.
\end{abstract}

DESCRITORES - Hidroxiapatita. Matriz óssea orgânica bovina. Ratos. Defeito ósseo.

\section{INTRODUÇÃO}

Diversos produtos sintéticos têm sido utilizados para o preenchimento de defeitos ósseos, bem como na indução da formação óssea, tais como proteína morfogenética $^{1,2,3}$, matriz óssea desmineralizada ${ }^{4} \mathrm{e}$ hidroxiapatita ${ }^{5,6}$. Para uma efetiva osteoindução, proteínas osteogênicas precisam ser implantadas com uma substância carreadora apropriada, desde que elas sejam solúveis em água e prontamente difusíveis? ${ }^{7}$.

1. Pesquisa realizada pelo Departamento de Cirurgia e Anestesiologia Veterinária, Faculdade de Medicina Veterinária e Zootecnia Unesp, Campus de Botucatu.

2. Bolsista $\mathrm{CNPq} / \mathrm{PIBIC}$, aluno do curso de graduação em Medicina Veterinária (FMVZ-Unesp Botucatu).

3. Prof ${ }^{\mathrm{a}}$ Ass. Dra - Departamento de Cirurgia e Anestesiologia da FMVZ-Unesp Botucatu.

4. Prof ${ }^{\mathrm{a}}$ Ass. Dr ${ }^{\mathrm{a}}$ - Departamento de Clínica Veterinária da FMVZ-Unesp Botucatu.

5. Prof- do Departamento de Bioquímica da FOB-USP.

6. Pós-graduando do Departamento de Cirurgia e Anestesiologia da FMVZ-Unesp Botucatu. 
URIST e colaboradores ${ }^{7}$ citaram que implantes de matriz óssea desmineralizada são mitogênicos e induzem a proliferação tecidual in vivo bem como in vitro. In vitro o desenvolvimento não vai além da condrogênese, ao passo que in vivo a condrogênese se prolonga para a osteogênese e desenvolvimento ósseo, que é induzido com igual consistência em locais esqueléticos ou extra esqueléticos.

BOLANDER e BALIAN ${ }^{4}$ produziram um defeito de $2 \mathrm{~cm}$ na ulna de 48 coelhos. Em cada animal, um defeito ulnar foi enxertado com matriz óssea desmineralizada revestida com plasma citratado autólogo, enquanto o outro defeito serviu como controle e foi enxertado com osso esponjoso autólogo da crista ilíaca, matriz óssea desmineralizada, ou matriz óssea desmineralizada aumentada com proteína óssea. $\mathrm{O}$ osso que foi induzido por enxertos com matriz óssea desmineralizada revestida com plasma mostrou ser tão forte quanto o osso formado após aplicação de osso esponjoso autólogo, sendo desta forma uma alternativa ao uso de autoenxerto.

Hidroxiapatita porosa (Interpore 500) foi utilizada, por HOLMES e colaboradores ${ }^{5}$, para o preenchimento de defeito ósseo induzido na metáfise tibial proximal de cães. O implante demonstrou um grau marcado de crescimento ósseo, sugerindo que o hospedeiro também proporcionou células osteoprogenitoras e fatores indutivos. Havia osso compacto ao longo da superfície externa e osso trabecular interiormente. O processo de incorporação final foi confirmado pelo encontro de $66,5 \%$ da superfície do Interpore 500 coberta com proliferação óssea em 12 meses.

LEMPERLE e colaboradores ${ }^{8}$ realizaram defeitos em mandíbulas e calvárias de cães, nos quais foram implantados enxerto ósseo autógeno e hidroxiapatita com a finalidade de avaliar o potencial osteocondutor. No defeito craniano, quando o periósteo não foi preservado, a regeneração ocorreu de maneira limitada; entretanto, sólida osteointegração ocorreu quando foi utilizado bloco de hidroxiapatita.

Três diferentes tipos de substitutos ósseos foram utilizados, por GAUTHIER e colaboradores ${ }^{6}$, para preencher um defeito da diáfise femoral em cães. Observaram bom resultado funcional em $83 \%$ dos implantes. Os substitutos de hidroxiapatita e polimetilmetacrilato foram sem sucesso, ao passo que a cerâmica de fosfato de cálcio mostrou melhor processo de cicatrização que o enxerto cortical.

SALATA e colaboradores ${ }^{9}$ compararam a cicatrização de defeitos ósseos induzidos no ramo mandibular de ratos tratados com ionômero, hidroxiapatita, ou estes materiais com regeneração óssea guiada. $\mathrm{O}$ uso da técnica de regeneração óssea guiada não aumentou o osso formado. Hidroxiapatita e substitutos ósseos ionômeros usados isoladamente foram mais efetivos em induzir o reparo de defeitos ósseos do que a membrana de regeneração óssea sozinha. $\mathrm{O}$ uso de hidroxiapatita foi associado com uma maior reação inflamatória do que o ionômero.

Para avaliar o uso de hidroxiapatita como implante em defeitos ósseos, REZENDE e colaboradores ${ }^{10}$, analisaram clínica e radiograficamente 14 cães submetidos a defeitos ósseos no terço proximal da tíbia direita. Verificaram que a hidroxiapatita osteointegrada pode ser considerada um substituto ósseo, sem causar reação inflamatória ou reação por corpo estranho.

Como a capacidade regenerativa do calvário é baixa, o mesmo tem sido um dos locais de escolha para pesquisas com agentes que estimulem a reparação ${ }^{1}$. Em vista disto, o trabalho teve por objetivos a observação da resposta biológica e poder indutor da combinação matriz óssea orgânica bovina e hidroxiapatita, desenvolvida pelo Departamento de Bioquímica da Faculdade de Odontologia da USP Bauru, em defeitos ósseos induzidos na calvária de ratos.

\section{MÉTODOS}

Foram empregados 20 ratos, Wistar, machos, com peso inicial médio entre 300 e 350 gramas, fornecidos pelo Biotério Central da UNESP- Botucatu, que foram divididos, por sorteio, em dois grupos eqüitativos e alocados em caixa de polietileno 40x60x18, com água e ração ad libitum.

Após jejum de 12 horas, os animais foram prémedicados com sulfato de atropina, na dose de $0,44 \mathrm{mg} /$ $100 \mathrm{~g}$ por via subcutânea, e anestesiados com uma mistura de xilazina $2 \%$ e ketamina $5 \%$ na proporção de $1: 1$, na dose de $0,2 \mathrm{ml}$ para cada $100 \mathrm{~g}$ de peso por via intramuscular. Feita tricotomia na região do crânio, foram posicionados em decúbito ventral e a anti-sepsia da área cirúrgica efetuada com álcool iodado. Foi realizada incisão de pele na linha média que se estendeu da protuberância occipital externa até a altura dos olhos. O tecido subcutâneo foi divulsionado e os músculos temporais e interescutulares afastados. O periósteo foi incisado e afastado. Foi removido um fragmento da porção mediana dos ossos parietais por meio de uma broca trefina média $(5 \mathrm{~mm})$, com o auxílio de um motor de baixa rotação. A dura-máter foi mantida íntegra. No grupo I o defeito foi preenchido com uma associação 
de matriz óssea orgânica bovina e hidroxiapatita, ao passo que no grupo II considerado controle, nada foi utilizado. $\mathrm{O}$ tecido subcutâneo foi aproximado com uma sutura contínua simples e a pele com pontos simples separados, empregando fio náilon monofilamento $\mathrm{n}^{0}$ 5-0.

Cinco animais de cada grupo foram submetidos à eutanásia com éter, aos 30 e 60 dias de pós-operatório. $\mathrm{O}$ osso parietal foi colhido e fixado em formalina tamponada a $10 \%$. Após a fixação, foram descalcificados e submetidos às técnicas rotineiras de Hematoxilina-Eosina para avaliação histológica. A leitura foi feita em microscopia óptica, visando observar o processo de reparação óssea.

Para cada variável avaliada no experimento (neoformação vascular, fibroblastos, osteoblastos, osteoclastos, reabsorção óssea e formação de cartilagem), as comparações entre os grupos em cada um dos momentos e entre os momentos em cada grupo foram pelo teste não paramétrico de Mann-Withney (ZAR,
1999 $)^{11}$, sendo consideradas diferenças significantes com $\mathrm{P}<0,05$. A quantificação de cada variável observada seguiu o esquema: ausente $=0$, discreta $=1(+)$, pequena $=2(++)$, moderada $=3(+++)$, acentuada $=4$ $(++++)$.

\section{RESULTADOS}

Quatro ratos morreram durante o procedimento cirúrgico e foram substituídos. Não foram observados, durante o período pós-operatório, sinais de infecção ou de lesões neurológicas. Na avaliação macroscópica das peças, verificou-se em todos os animais que o defeito estava preenchido, porém com densidade inferior ao osso circunvizinho.

$\mathrm{Na}$ avaliação histológica dos animais do grupo I, aos 30 dias de pós-operatório, havia grande quantidade de osteoblastos e aparecimento de cartilagem, ao passo que no grupo II (controle) ainda estava ocorrendo processo de reabsorção e presença de grande quantidade de osteoclastos (Figura 1).



Grupo I

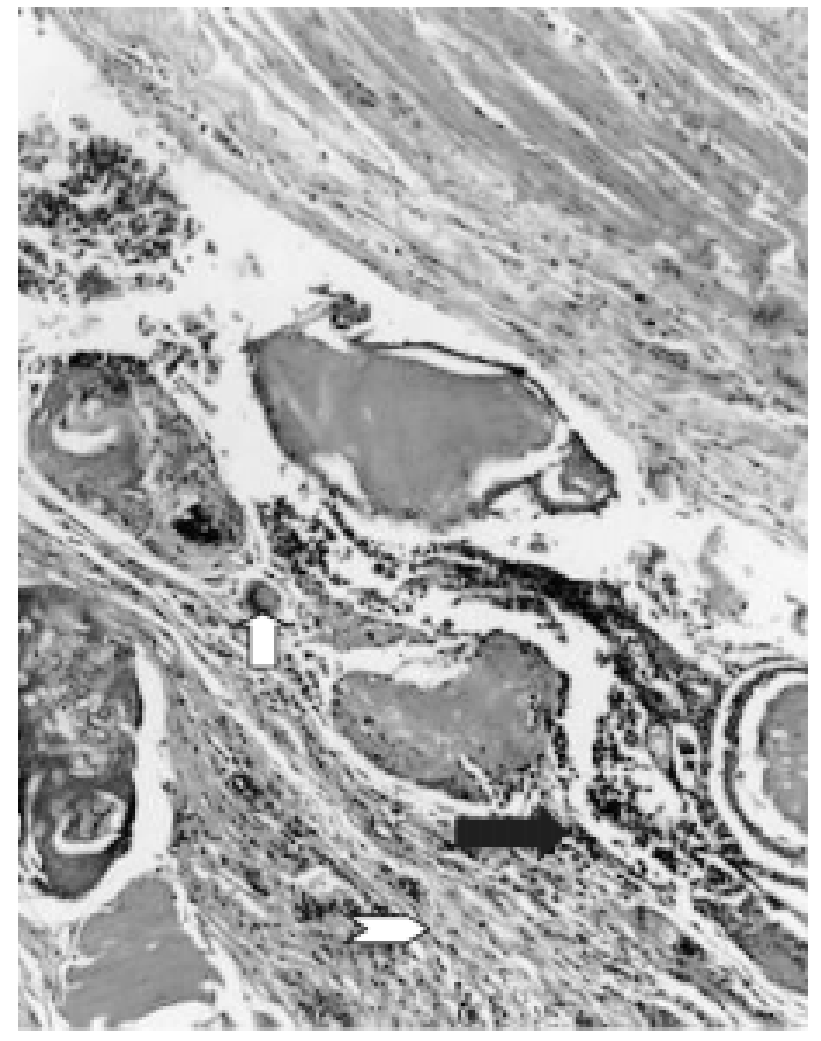

Grupo II

FIGURA 1 - Processo de reparação óssea em animais dos grupos I e II aos 30 dias de pós-operatório. Observa-se no grupo I nítida neovascularização $(\Rightarrow$ ) e tecido ósseo neoformado $(+)$ com barreira de osteoblastos $(\boldsymbol{y})$ subjacente e no grupo II infiltrado inflamatório mononuclear ( $\Rightarrow$ ), osteoclastos ( $\hat{v}$ ) e desorganização de fibras colágenas $(\Xi)$ (HE - 25x, AO) 
Aos 60 dias de pós-operatório, apenas os ratos do grupo I apresentavam osso mineralizado e o defeito quase totalmente reparado (Figura 2).



Grupo I

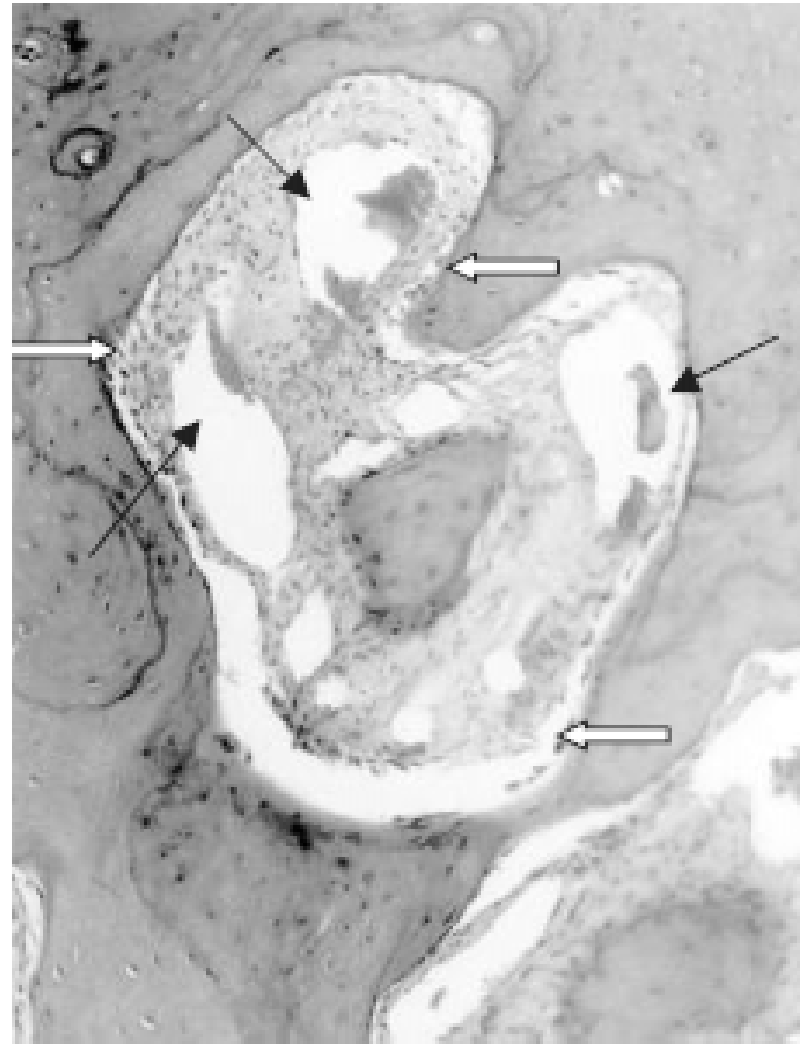

Grupo II

FIGURA 2 - Processo de reparação óssea em animais dos grupos I e II aos 60 dias de pós-operatório. Observa-se no grupo I o defeito ósseo ainda não consolidado, proliferação osteoblástica com deposição de matriz óssea não mineralizada ( $)$ entre duas áreas de matriz óssea mineralizada e organizada $(\boldsymbol{\uparrow})$. No grupo II a reparação encontra-se desorganizada com evidente neovascularização (ע) e proliferação osteoblástica $(\Rightarrow)$. ( $\mathrm{HE}-25 \mathrm{x}, \mathrm{AO})$

Não foram detectados sinais de reação por corpo estranho no grupo I, bem como sinais de reação inflamatória. No grupo II foram verificadas aderências do cérebro à região óssea em dois animais no $30^{\circ}$ dia e em um no $60^{\circ}$ dia de pós-operatório.

Pela análise estatística (Tabela 1) observou-se, aos 60 dias de pós-operatório, diminuição de neovasos nos animais de ambos os grupo e diminuição da quantidade de fibroblastos no grupo II. A quantidade de osteoblastos diferiu entre os grupos aos 60 dias de pós-operatório, sendo maior no grupo I. Os osteoclastos não diferiram entre os grupos e entre os momentos. A reabsorção óssea foi maior no grupo II aos 30 dias de pós-operatório e no grupo I não foi verificada diferença entre os momentos; entre os grupos não foram observadas diferenças. A presença de cartilagem não diferiu entre os momentos de um mesmo grupo, porém houve diferença estatística entre os grupos I e II aos 30 dias, sendo maior no grupo I. 
TABELA 1 - Medianas, de 5 repetições, de neovasos, fibroblastos, osteoblastos, osteoclastos, reabsorção óssea e presença de cartilagem, segundo grupos (I - combinação matriz óssea orgânica e hidroxiapatita, II - controle) e momentos de avaliação.

\begin{tabular}{l|c|c|c}
\hline \multicolumn{1}{c|}{ Variável } & Grupos & $\mathbf{3 0}$ dias & $\mathbf{6 0}$ dias \\
\hline Neovasos & I & $2 \mathrm{aA}$ & $0 \mathrm{bB}$ \\
& II & $3 \mathrm{aA}$ & $\mathrm{bB}$ \\
\hline Fibroblastos & I & $2 \mathrm{a} A^{*}$ & $1 \mathrm{aB}$ \\
& II & $3 \mathrm{aA}$ & $2 \mathrm{bB}$ \\
\hline Osteoblastos & I & $3 \mathrm{aA}$ & $3 \mathrm{aA}$ \\
& II & $2 \mathrm{aA}$ & $2 \mathrm{aB}$ \\
\hline Osteoclastos & I & $0 \mathrm{aA}$ & $0 \mathrm{aB}$ \\
& II & $1 \mathrm{aA}$ & $0 \mathrm{aB}$ \\
\hline Reabsorção Óssea & I & $0 \mathrm{aA} *$ & $0 \mathrm{aB}$ \\
& II & $1 \mathrm{aA}$ & $0 \mathrm{bB}$ \\
\hline Presença de Cartilagem & I & $1 \mathrm{aA} *$ & $1 \mathrm{aB}$ \\
& II & $0 \mathrm{aB}$ & $1 \mathrm{aB}$ \\
\hline
\end{tabular}

* para cada grupo, letras minúsculas diferentes indicam diferença significativa entre os momentos de avaliação; para cada momento de avaliação, letras maiúsculas diferentes indicam diferença significativa entre os grupos.

\section{DISCUSSÃO}

Mesmo considerando que a capacidade regenerativa do calvário é baixa ${ }^{1}$, o fato dos defeitos ósseos terem sido preenchidos em ambos os grupos, provavelmente está associado à manutenção do periósteo, visto que LEMPERLE e colaboradores ${ }^{8}$ observaram que defeitos calvários em cães regeneraram de maneira limitada quando o periósteo não foi preservado. Outro fator a ser considerado é que o defeito induzido foi de $0,5 \mathrm{~cm}$ de diâmetro e, segundo URIST e colaboradores ${ }^{7}$, em crânio de ratos, apenas defeitos de $0,8 \mathrm{~cm}$ de diâmetro são incapazes de reparo espontâneo.

As aderências do cérebro à região óssea apenas em animais do grupo II são indícios de que a combinação hidroxiapatita e matriz óssea orgânica bovina não foi irritante aos tecidos circunvizinhos. Da mesma forma não foram detectados sinais de reação inflamatória ou por corpo estranho com o uso destes biomaterias, fato também descrito por REZENDE e colaboradores ${ }^{10}$ ao empregarem hidroxiapatita como substituto ósseo em cães, e diferentemente do observado por SALATA e colaboradores ${ }^{9}$, que tiveram maior reação inflamatória com o uso de hidroxiapatita do que com o ionômero em defeitos ósseos induzidos no ramo mandibular de ratos.

A presença de neovasos e fibroblastos é importante no estágio inicial de reparação óssea ${ }^{12}$. Embora os neovasos não tenham diferido entre os grupos, os fibroblastos, responsáveis pela secreção de procolágeno ${ }^{12}$, permaneceram no grupo I aos 30 e 60 dias, ao passo que no grupo II houve diminuição, indicando que a combinação dos produtos estimulou esta variável.

A reabsorção óssea no grupo I não diferiu entre os momentos, provavelmente o produto minimizou as alterações iniciais do processo de reparação, comparativamente ao grupo II em que esta foi mais intensa aos 30 dias. Por outro lado, não ocorreu diferença estatisticamente significante no número de osteoclastos entre os grupos e momentos.

A presença de cartilagem foi estatisticamente maior no grupo I aos 30 dias de pós-operatório, representando uma aceleração na condrogênese. Da mesma forma, os osteoblastos, responsáveis pela formação da matriz óssea $^{12}$, diferiram aos 60 dias entre os grupos, sendo maior no grupo I. Estes fatos podem estar associados à matriz óssea orgânica bovina, que segundo URIST e colaboradores $^{7}$ é mitogênica e induz proliferação tecidual, bem como a ação osteocondutora da hidroxiapatita ${ }^{8}$.

Quando utilizadas de maneira isolada, tanto a hidroxiapatita ${ }^{5,8,9}$ como a matriz óssea desmineralizada ${ }^{4}$, mostraram efeito positivo na reparação óssea; fato semelhante foi observado no grupo I ao combinar estes produtos, uma vez que histologicamente já havia presença 
de cartilagem aos 30 dias e início de mineralização óssea aos 60 dias de pós-operatório. Este achado difere de GAUTHIER e colaboradores ${ }^{6}$, que não obtiveram sucesso no que diz respeito à reparação do defeito ósseo, quando utilizaram hidroxiapatita isoladamente.

\section{CONCLUSÕES}

A combinação matriz óssea orgânica bovina e hidroxiapatita não causou reações adversas e favoreceu a reparação óssea.

\section{REFERÊNCIAS}

1. Sato K, Urist MR. Induced regeneration of calvaria by bone morphogenetic protein (BMP) in dogs. Clin Orthop 1985; 197:301-11.

2. Nilsson OS, Urist MR, Dawson EG, Schmalzried TP, Finerman GAM. Bone repair induced by bone morphogenetic protein in ulnar defects in dogs. J Bone Joint Surg 1986; 68-B(4):635-42.

3. Yasko AW, Lane JM, Fellinger EJ, Rosen V, Wozney JM, Wang EA. The healing of segmental bone defects, induced by recombinant human bone morphogenetic protein (rhBMP2). J Bone Joint Surg 1992;74-A(5):659-70.

4. Bolander ME, Balian G. The use of demineralized bone matrix in the repair of segmental defects. J Bone Joint Surg 1986; 68A(8): 1264-73.
5. Holmes RE, Bucholz RW, Mooney V. Porous hydroxyapatite as a bone-graft substitute in metaphyseal defects. J Bone Joint Surg 1986; 68-A(6):904-11.

6. Gauthier O, Gouin F, Aguado E, Passuti N, Daculsi G. Biomaterials for bone substitution and bone allografts: compared study in full weight-bearing conditions. Revue Méd Vét $1997 ; 148(10): 813-22$.

7. Urist MR, DeLange RJ, Finerman GAM. Bone cell differentiation and growth factors. Science 1983; 220:680-5.

8. Lemperle SM, Calhoun CJ, Curran RW, Holmes RE. Comparison of protected bone regeneration, osteoconduction with coralline hydroxyapatite implants, and cancellous bone autografts in large cranial and mandibular defects in dogs. Plastic Surg 1996;47:723-7.

9. Salata LA, Craig GT, Brook IM. Bone healing following the use of hydroxyapatite or ionomeric bone substitutes alone or combined with a guided bone regeneration technique: an animal study. J Oral Maxillofac Implants 1998;13(1):44-51.

10. Rezende CMF, Borges APB, Bernis WO, Melo EG, Nobrega Neto PI. Aspectos clínico-cirúrgicos e radiográficos da hidroxiapatita sintética na diáfise proximal da tíbia de cães. Arq Bras Med Vet Zootec 1998; 50(5):537-45.

11. Zar JH. Two-sample hypotheses. In: Zar JH. Biostatistical Analysis. 4ed. New Jersey: Prentice Hall;1999. p 122-60.

12. Banks WJ. Tecidos de sustentação: osso. In: Banks WJ. Histologia veterinária aplicada. 2ed. São Paulo: Manole; 1992. p 137-66.

Braz F, Rahal S C, Rocha N S, Taga E, Biasi F. Use of bovine organic bone matrix and hydroxyapatite in repair of skull defects in rats. Acta Cir Bras [serial online] 2003 Jan-Feb;18(1). Available from URL: http://www.scielo.br/acb.

ABSTRACT - Purpose: The aim of this study was to evaluate the biological response and inductor effect of the hydroxyapatite combined with bovine organic bone matrix. Methods: Skull defects were induced on 20 male albino rats, with initial body weight between 300 and 350 grams. The animals were divided into two groups. In group I the defect was filled with hydroxyapatite combined with bovine organic bone matrix, and in group II no product was used. Five animals of each group were euthanised 30 and 60 days after the surgery for histopathological evaluation. Results: Bone reabsorption was more evident in the group II at 30 days post surgery. There was no difference on presence of cartilage between moments in the same group. Statistical difference was observed between group I and II at 30 days after the surgery. At day 60 post surgery, animals from group I showed a higher quantity of osteoblasts and cartilage compare to group II. Conclusion: It was possible to conclude that hydroxyapatite combined with bovine organic bone matrix does not produce adverse reaction and induce bone repair.

KEY WORDS - Hydroxyapatite. Bovine organic bone matrix. Rats.

Conflito de interesse: nenhum Fonte de financiamento: CNPq/PIBIC

Correspondência:

Fabiano Braz

Av. Camilo Mazoni, 1052

18610-460 Botucatu - SP

Tel: (14) 6824-1741

fabiano_braz@hotmail.com

Data do recebimento: $24 / 09 / 2002$

Data da revisão: 18/10/2002

Data da aprovação: 04/11/2002 